\title{
Individual differences in temperaments traits and complex network properties of fMRI
}

\author{
Sunghyon Kyeong*, Won Sup Kim, Dong-Uk Hwang \\ From Twenty First Annual Computational Neuroscience Meeting: CNS*2012 \\ Decatur, GA, USA. 21-26 July 2012
}

In the previous study, Cloninger's psychobiological model of personality $[1,2]$ revealed that temperament traits are genetically determined. Thus, it is postulated that temperament traits determine one's disposition to the early emotions of fear, anger and attachment and one's automatic behavioral responses to the environmental stimuli of danger, novelty and reward. The previous studies have revealed the correlational tendency between the brain volume size and temperament traits $[3,4]$. However, only a few studies reported that neural correlates of the temperament traits in the resting state functional network. Thus, it is required to analyze function network and its neural correlates of temperament traits to advance our understanding on how psychobiological properties are correlated to functional network.

Forty young male volunteers (mean age $=25.2 \pm 3.3$ years) took part in this experiment. None of these participants had a history of traumatic brain injury, epilepsy, or other neurological and psychiatric problems. The present study was approved by the Institutional Review Board of Severance Hospital, and all volunteers gave informed consent before participating this experiment. The Korean version of the temperament and character inventory (TCI) was used to assess temperament and character factors of all participants [5]. The participants underwent the resting state fMRI scanning ( 404 volumes with $T R=2000 \mathrm{~ms}$ ). The participants were instructed to keep resting state with eyes closed. After applying the spatiotemporal preprocessing, we divided the whole brain regions into 1000 sub-regions by using the previously reported methods [6] and obtained the mean time series for each sub-region. The adjacency matrix was investigated by using the Pearson's correlation coefficients between all pairs of mean time series. We

\footnotetext{
* Correspondence: skyeong@nims.re.kr

Division of Computational Sciences in Mathematics, National Institute for

Mathematical Sciences, Daejeon, Republic of Korea
}

measured network properties and performed group comparisons of the network measures.

The $k$-means clustering algorithm with three temperament personality traits (i.e. NS, HA, and RD scores) of 40 subjects separates the sample data into two groups. 18 (22) subjects are classified as obsessional (histrionic) personality group. The correlation analysis of temperament traits and the complex network measures show that the node strength in right middle frontal, right supplementary motor areas has decreased in OP. However node strength in right cerebellum has increased in OP.

\section{Conclusion}

Our study was the first attempt to distinguish personality disorder subtypes by using $k$-means clustering algorithm with three temperament traits. Based upon the clustering results, we performed statistical comparison on network measures between histrionic and obsessional personality groups.

Published: 16 July 2012

\section{References}

1. Cloninger CR: A unified biosocial theory of personality and its role in the development of anxiety states. Psychiatric developments 1986, 4(3):167-226.

2. Cloninger CR, Svrakic DM, Przybeck TR: A psychobiological model of temperament and character. Archives of general psychiatry 1993, 50(12):975-990.

3. Gardini Simona, Cloninger C Robert, Venneri Annalena: Individual differences in personality traits reflect structural variance in specific brain regions. Brain Research Bulletin 2009, 79:265-270.

4. lidaka Tetsuya, Matsumoto Atsushi, Ozaki Norio, Suzuki Tatsuyo, Iwata Nakao, Yamamoto Yukiko, Okada Tomohisa, Sadato Norihiro: Volume of left amygdata subregion predicted temperamental trait of harm avoidance in female young subjects. A voxel-based morphometry study. Brain Research 2006, 1125:85-93.

5. Sung SM, Kim JH, Yang E, Abrams KY, Lyoo IK.: Reliability and validity of the Korean version of the Temperament and Character Inventory. Comprehensive psychiatry 2002, 43(3):235-43.
C 2012 Kyeong et al; licensee BioMed Central Ltd. This is an Open Access article distributed under the terms of the Creative Commons Attribution License (http://creativecommons.org/licenses/by/2.0), which permits unrestricted use, distribution, and reproduction in any medium, provided the original work is properly cited. 
6. Zalesky Andrew, et al: Whole-brain anatomical networks: Does the choice of nodes matter? Neuroimage 2010, 50:970-983.

doi:10.1186/1471-2202-13-S1-P114

Cite this article as: Kyeong et al: Individual differences in

temperaments traits and complex network properties of fMRI. BMC

Neuroscience 2012 13(Suppl 1):P114.

Submit your next manuscript to BioMed Central and take full advantage of:

- Convenient online submission

- Thorough peer review

- No space constraints or color figure charges

- Immediate publication on acceptance

- Inclusion in PubMed, CAS, Scopus and Google Scholar

- Research which is freely available for redistribution

Submit your manuscript at 